\title{
Interdiffusion in amorphous Si/Ge multilayers by Auger depth profiling technique
}

\author{
A. Csik, G. A. Langer, D. L. Beke, ${ }^{\text {a) }}$ and Z. Erdélyi \\ Department of Solid State Physics, University of Debrecen, P.O. Box 2, H-4010 Debrecen, Hungary \\ M. Menyhard and A. Sulyok \\ Research Institute for Technical Physics and Materials Science, P.O. Box 49, H-1525 Budapest, Hungary
}

(Received 9 May 2000; accepted for publication 12 October 2000)

\begin{abstract}
It has been shown by the Auger depth profiling technique that the concentration profile at the initially sharp $\mathrm{Si} / \mathrm{Ge}$ interface in amorphous $\mathrm{Si} / \mathrm{Ge}$ multilayers shifted but remained still sharp after a heat treatment at $680 \mathrm{~K}$ for $100 \mathrm{~h}$. At the same time the fast diffusion of Si resulted in the formation of an almost homogeneous $\mathrm{Ge}(\mathrm{Si})$ amorphous solid solution, while there was practically no diffusion of Ge into the Si layer. This is direct evidence on the strong concentration dependence of the interdiffusion coefficient in amorphous $\mathrm{Si} / \mathrm{Ge}$ system, and it is in accordance with the previous indirect result obtained from the measurements of the decay of the small angle Bragg peaks, as well as with finite difference simulations. (C) 2001 American Institute of Physics.
\end{abstract}

[DOI: $10.1063 / 1.1331330]$

Changes in atomic structures of amorphous semiconductors and their relationships to physical properties are currently of interest due to their useful optical and electronic features. ${ }^{1,2}$ Since most structural changes are related to atomic diffusion, any real understanding of the structural transformation, homogenization, etc., must be based on the knowledge of the diffusion processes. The study of diffusion in amorphous materials includes some difficulties. One of the main problems is related to the thermal stability of the amorphous phase; the diffusional measurements should be carried out at low temperatures for very short diffusion times in order to avoid structural changes due, e.g., to structural relaxation. Additionally, in amorphous semiconductors the mechanism of diffusion is also not fully understood. ${ }^{3-5}$ Thus, for example factors controlling the details of diffusional homogenization in amorphous $\mathrm{Si} / \mathrm{Ge}$ multilayers are still under discussion. First of all the diffusional asymmetry (manifested in the strong concentration dependence of the interdiffusion coefficients), ${ }^{6}$ the significant pore formation during the diffusional mixing, ${ }^{7}$ and the possible role of diffusional stresses ${ }^{8}$ are the most important factors indicating the need of a better understanding of the previous process.

In this article interdiffusion in amorphous $\mathrm{Si}-\mathrm{Ge}$ multilayered specimens is studied by Auger depth profiling. The primary objective of the present investigation is to observe the predicted asymmetric change of composition caused by the strong concentration dependence of the diffusion coefficients. Experimental results, obtained from small angle x-ray diffraction (SAXRD) measurements at different average compositions indicated a strong concentration dependence of the chemical diffusion parameters. ${ }^{9,10}$ Although such a strong concentration dependence inevitably should lead to a significant curvature on the $\ln \left(I / I_{0}\right)\left(I / I_{0}\right.$ is the normalized height of the first order SAXRD peak) versus time plots ${ }^{11}$

\footnotetext{
${ }^{a)}$ Electronic mail: dbeke@delfin.klte.hu
}

(and to oscillatory behavior of the higher order peaks), later on the experimentally observed curvature was rather attributed by the same group to the effects of structural relaxation and coupling back effects of stresses of diffusional origin were also excluded. ${ }^{12}$ These effects were theoretically investigated by Beke et al. using finite difference calculations assuming that the binary system is ideal. ${ }^{8,13}$ It was found, that for a strong concentration dependence of the intrinsic diffusion coefficients the diffusion profile should have a very asymmetrical shape: the homogenization took place by subsequent dissolution of $\mathrm{Si}$ into the $\mathrm{Ge}$, where the Si homogeneously distributed during a relatively short time. On the other hand, there was practically no diffusion of $\mathrm{Ge}$ into $\mathrm{Si}$ (Fig. 1).

Good quality amorphous $\mathrm{Si} / \mathrm{Ge}$ multilayers, as was checked by transmission electron microscope, were prepared by dc magnetron sputtering ${ }^{6}$ from elemental targets onto (001) silicon wafers. The modulation wavelength was designed to range from 10 to $20 \mathrm{~nm}$ with nearly equal thickness of sublayers, which were monitored in situ using vibrating quartz crystal method. The total thickness of the Si/Ge films was approximately $60-120 \mathrm{~nm}$. For annealing, the specimen were placed in high purity (99.999\%) Ar atmosphere. The annealing treatments were carried out at $680 \mathrm{~K}$ to prevent the crystallization of amorphous Ge. ${ }^{14}$

The structure of the specimens before (as received) and after the heat treatment were determined by Auger depth profiling by applying a dedicated depth profiling device ${ }^{15}$ using the following parameters: ion energy $0.8 \mathrm{keV}$; angle of incidence (with respect to the surface normal) $80^{\circ}$; type of ion $\mathrm{Ar}^{+}$, and the specimen was rotated during ion sputtering. The sputtering rate of silicon and germanium using these sputtering conditions are the same ${ }^{16}$ and thus the sputtering time can be readily transformed to sputter depth. For Auger analysis the following Auger peaks have been recorded: Ge $52 \mathrm{eV}$ and Si $92 \mathrm{eV}$. The small Ge Auger peak of $89 \mathrm{eV}$ 


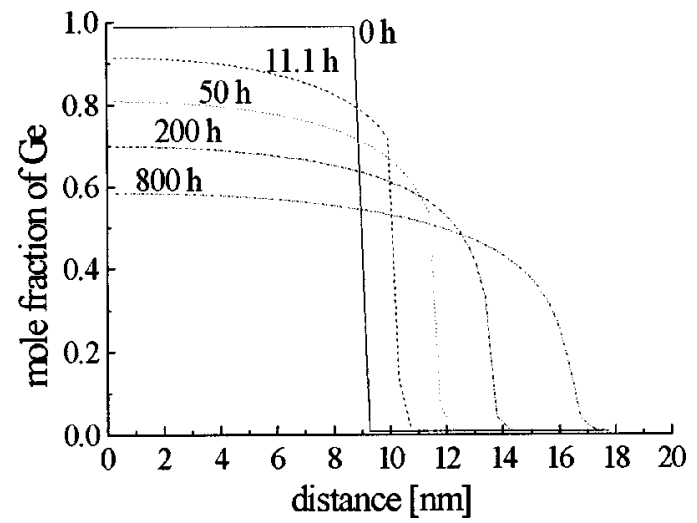

FIG. 1. Results of simulations of the diffusion process (see Ref. 8); concentration distribution at different annealing time.

overlaps with the measured $\mathrm{Si}$ peak thus the later was corrected by assuming that the alloying (mixing) of $\mathrm{Ge}$ and $\mathrm{Si}$ does not influence the peak shapes. The concentration was calculated by comparing the corrected Si peak with that measured on pure silicon substrate; correction for backscattering was made. ${ }^{16}$

Because of the ion sputtering induced alterations the measured depth profile is a distorted version of the original concentration distribution. A recently developed trial and error method was used to calculate the original concentration distribution from the measured depth profile. ${ }^{16,17}$ This method supposes that the majority of the ion induced alteration is due to ballistic mixing (which assumption is satisfied for this case, since the other important distorting process the surface roughening results in less than $1 \mathrm{~nm}$ rms roughness using the earlier sputtering parameters), ${ }^{18}$ which is properly described by TRIM simulation. ${ }^{17,19}$ The method also considers the intrinsic interface roughness or waviness by a Gaussian broadening.

Figure 2 shows one period of the measured depth profiles for the as received and annealed specimens, respectively. It is clear that the structure of specimen changed due to the annealing; the thickness of the silicon layer decreased, and the silicon concentration in the germanium layer increased. On the other hand, no germanium could be observed in the silicon layer. It should be mentioned that silicon was also present in the germanium layer of the as received specimen. This silicon can be attributed to some contamination of the sputtering system.

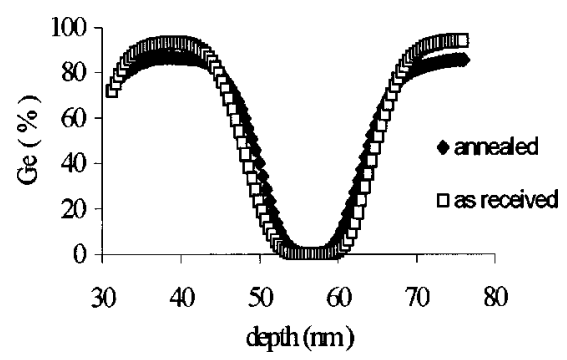

FIG. 2. One period of the measured depth profiles for the as-received and annealed specimens.

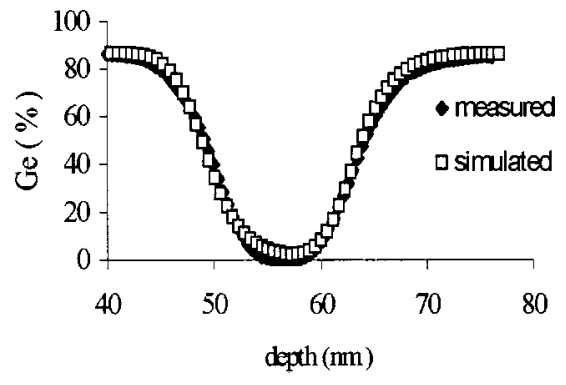

FIG. 3. Measured and simulated depth profiles for the annealed specimen.

In the case of the as-received specimen the best agreement between the measured and simulated depth profiles was obtained by supposing an original structure of $19 \mathrm{~nm}$ $\mathrm{Ge}(94 \%) \mathrm{Si}(6 \%)$ and $17 \mathrm{~nm}$ pure $\mathrm{Si}$, and an interface waviness of $1.8 \mathrm{~nm}$ amplitude. Applying this method we determined the thicknesses of all layers in the specimen (supposing the same waviness) to be $18.6 \pm 0.6$ and $17.2 \pm 0.5 \mathrm{~nm}$ for the $\mathrm{Ge}(94 \%) \mathrm{Si}(6 \%)$ and pure $\mathrm{Si}$ layer, respectively. These thicknesses slightly differ from the nominal ones $(18 \mathrm{~nm}$ $\mathrm{Si} / 18 \mathrm{~nm} \mathrm{Ge}$ ). Figure 3 shows the measured and simulated depth profiles (assuming the same waviness) for a period of the depth profiles in the case of the heat treated specimen. In this case we have obtained, considering all the layers, the following structure: $21.3 \pm 0.7 \mathrm{~nm} \mathrm{Ge}(86 \%) \mathrm{Si}(14 \%)$ and 14 $\pm 0.5 \mathrm{~nm}$ pure $\mathrm{Si}$.

These results clearly show that the diffusion is really very asymmetric. In accordance with the results of our calculations ${ }^{8}$ the silicon could enter into the germanium layer but the germanium could not diffuse into the silicon. At the same time, due to the silicon diffusion to germanium, the germanium layer became thicker and the thickness of Si decreased from 17 to $14 \mathrm{~nm}$. It is also clear that during the heat treatment the sharpness of the interface remained the same, which is also in accordance with our calculations. ${ }^{8}$ On the other hand, our results clearly indicate that the interdiffusion coefficient should strongly depend on the concentration and consequently measurements based on the SAXRD of multilayers cannot be interpreted by neglecting nonlinear effects and/or relying, e.g., on the effects of structural relaxation's alone. For further discussion see Ref. 20. It is also interesting to note that surprisingly there is no classical (bulk) interdiffusion result published in crystalline $\mathrm{Si} / \mathrm{Ge}$ system, ${ }^{21}$ in which a similar diffusional asymmetry is expected. In our opinion this is due to the shift of a sharp interface instead of getting a flattening concentration profile, as well as, to the possible mechanical failure of such diffusion couples caused by the sharp peak of tensile stress in silicon. ${ }^{22}$

In conclusion the Auger depth profiling technique provided direct evidence on the asymmetric interdiffusion in amorphous $\mathrm{Si}-\mathrm{Ge}$ system. Due to the strong concentration dependence of the interdiffusion coefficient, the silicon almost homogeneously had been distributed in the Ge layer and there was practically no Ge diffusion into the $\mathrm{Si}$.

OTKA Board of the Hungarian Academy of Sciences (T-30430, T-025485, and T-025525), FKFP/453/1997 and FKFP-0325/2000 Grant of Hungarian Ministry of Education, 
and EU INCO COPERNICUS ERBICIC 15CT960800 project supported this work. The authors thank Dr. L. Daróczi for taking our transmission electron microscopy pictures.

${ }^{1}$ NATO ASI Series 234, (1993).

${ }^{2}$ A. Fert, Mater. Sci. Forum 59-60, 439 (1990).

${ }^{3}$ G. T. Barkema and N. Mousseau, Phys. Rev. Lett. 81, 1865 (1998).

${ }^{4}$ G. Müller, G. Krötz, S. Kolbitze, and G. N. Greaves, Philos. Mag. B 69, 177 (1994).

${ }^{5}$ S. D. Theiss, F. Spaepen, and M. J. Aziz, Appl. Phys. Lett. 68, 1226 (1996).

${ }^{6}$ D. L. Beke, G. A. Langer, M. Kis-Varga, A. Dudas, P. Nemes, L. Daróczi, Gy. Kerekes, and Z. Erdélyi, Vacuum 50, 373 (1998).

${ }^{7}$ L. Daróczi, D. L. Beke, G. Langer, Gy. Radnóczi, and Zs. Czigány, J. Magn. Magn. Mater. 156, 417 (1996).

${ }^{8}$ D. L. Beke, P. Nemes, Z. Erdélyi, I. A. Szabó, and G. A. Langer, Mater. Res. Soc. Symp. Proc. 528, 99 (1998).

${ }^{9}$ C. Janot., M. Roth, and G. Marchal, J. Phys. 47, 1751 (1986).
${ }^{10}$ S. M. Prokes and F. Spaepen, Mater. Res. Soc. Symp. Proc. 177, 305 (1987).

${ }^{11}$ A. L. Greer and F. Spaepen, in Synthetic Modulated Structures, edited by L. L. Chang and Giessen (Academic, New York, 1985), p. 419.

${ }^{12}$ F. Spaepen, J. Magn. Magn. Mater. 156, 407 (1996); A. S. Witvrouw and F. Spaepen, J. Appl. Phys. 74, 7154 (1993).

${ }^{13}$ Z. Erdélyi, D. L. Beke, P. Nemes, and G. A. Langer, Philos. Mag. A 79, 1757 (1999)

${ }^{14}$ E. P. Donovan, F. Spaepen, D. Turnbull, J. M. Poate, and D. C. Jacobson, J. Appl. Phys. 57, 1795 (1985).

${ }^{15}$ A. Barna and M. Menyhard, Phys. Status Solidi A 145, 263 (1994).

${ }^{16}$ M. Menyhard, A. Barna, J. P. Biersack, K. Järrendhal, and J.-E. Sundgren, J. Vac. Sci. Technol. A 13, 1999 (1995).

${ }^{17}$ M. Menyhard, Surf. Interface Anal. 26, 1001 (1998).

${ }^{18}$ A. Barna, B. Pécz, and M. Menyhard, Ultramicroscopy 70, 161 (1998).

${ }^{19}$ J. P. Biersack, Nucl. Instrum. Methods Phys. Res. B 27, 21 (1987).

${ }^{20}$ A. Csik, D. L. Beke, G. A. Langer, L. Daróczi, M. Kis-Varga, and Z. Erdélyi (unpublished).

${ }^{21} \mathrm{~N}$. Stolwijk and H. Bracht, in Landolt-Börnstein, edited by M. Mehrer (Springer, Berlin, 1998), Vol. III-33A, pp. 2-249.

${ }^{22} \mathrm{P}$. Gas (private communication). 